\title{
Gene Selection, Alternative Splicing, and Post-translational Processing Regulate Neuroligin Selectivity for $\beta$-Neurexins ${ }^{\dagger}$
}

\author{
Davide Comoletti, ${ }^{\ddagger}$ Robyn E. Flynn, ${ }^{\ddagger}$ Antony A. Boucard, ${ }^{\S}$ Borries Demeler," Virgil Schirf, Jianxin Shi, \\ Lori L. Jennings, ${ }^{\ddagger}$ Helen R. Newlin, $¥$ Thomas C. Südhof, ${ }^{\S, \perp, \# ~ a n d ~ P a l m e r ~ T a y l o r *, ~}$ \\ Department of Pharmacology, University of California-San Diego, La Jolla, California 92093-0636, Center for Basic \\ Neuroscience, Department of Molecular Genetics, and Howard Hughes Medical Institute, University of Texas Southwestern \\ Medical Center, Dallas, Texas 75235, and Department of Biochemistry, The University of Texas Health Science Center,
} San Antonio, Texas 78229

Received July 13, 2006; Revised Manuscript Received August 29, 2006

\begin{abstract}
Neuroligins $1-4$ are postsynaptic transmembrane proteins capable of initiating presynaptic maturation via interactions with $\beta$-neurexin. Both neuroligins and $\beta$-neurexins have alternatively spliced inserts in their extracellular domains. Using analytical ultracentrifugation, we determined that the extracellular domains of the neuroligins sediment as dimers, whereas the extracellular domains of the $\beta$-neurexins appear monomeric. Sedimentation velocity experiments of titrated stoichiometry ratios of $\beta$-neurexin and neuroligin suggested a 2:2 complex formation. The recognition properties of individual neuroligins toward $\beta$-neurexin-1 (NX1 $\beta$ ), along with the influence of their splice inserts, were explored by surface plasmon resonance and affinity chromatography. Different neuroligins display a range of NX1 $\beta$ affinities spanning more than 2 orders of magnitude. Whereas splice insert 4 in $\beta$-neurexin appears to act only as a modulator of the neuroligin/ $\beta$-neurexin association, splice insert B in neuroligin-1 (NL1) is the key element regulating the NL1/NX1 $\beta$ binding. Our data indicate that gene selection, mRNA splicing, and post-translational modifications combine to give rise to a controlled neuroligin recognition code with a rank ordering of affinities for particular neurexins that is conserved for the neuroligins across mammalian species.
\end{abstract}

In the mammalian central nervous system, the development and maintenance of a functional neuronal network is based on specific cell-cell recognition and communication through synaptic connections. The pre- and postsynaptic components of synapses are linked together by homophilic molecules, such as cadherins and synCAM, and heterophilic molecules, such as neuroligins and neurexins $(1-3)$. However, the mechanism by which specificity of synaptic recognition is achieved during development and for maintaining plasticity is far from being resolved.

The neuroligins comprise a family of five genes encoding single transmembrane-spanning proteins, with a sequence identity in their extracellular domains of greater than $70 \%$ $(4,5)$. For the same neuroligin, sequence identity among mammalian species exceeds $98 \%$. Neuroligin- $1(\mathrm{NL} 1)^{1}$ is

$\dagger$ This work was supported by USPHS Grants P42-ES-10337 and R37 GM-18360 to P.T., Cure Autism Now Pilot Grant and National Alliance for Autism Research Grant 843 to D.C., Fonds de la Recherche en Santé du Québec to A.A.B., R37 MH52804-08 to T.C.S., and NSF DBI-9974819 to B.D.

* To whom correspondence should be addressed: Department of Pharmacology, University of California-San Diego, La Jolla, CA 92093-0636. Telephone: 858-534-1366. Fax: 858-534-8248. E-mail: pwtaylor@ucsd.edu.

University of California-San Diego.

$\S$ Center for Basic Neuroscience, University of Texas Southwestern Medical Center.

"The University of Texas Health Science Center.

${ }^{\perp}$ Department of Molecular Genetics, University of Texas Southwestern Medical Center.

\# Howard Hughes Medical Institute, University of Texas Southwestern Medical Center. expressed mainly in neurons at excitatory postsynaptic sites $(4,6)$, whereas neuroligin-3 (NL3) is also expressed in glia and dorsal root ganglia, suggesting the additional possibility of neuroligin-mediated glia-glia and glia-neuron interactions $(7,8)$. Neuroligins $2-4$ (NL2-NL4) were found in several peripheral tissues, where $\beta$-neurexin expression is not detectable $(5,9,10)$. At the cellular level, NL1, NL3, and NL4 cluster in excitatory synapses, whereas NL2 is found enriched at inhibitory synapses in both rat brain and dissociated neurons $(6,11,12)$. The expression of recombinant NL1-NL3 in non-neuronal cells is known to induce presynaptic differentiation in co-cultured hippocampal neurons $(3,13)$.

The extracellular domain of NL1 contains two regions of alternative splicing. The first region (splice insert A, NL1 residues 165-184) gives rise to two potential inserts: insert A1 has a calculated charge of +8 and an internal disulfide bond formed between Cys 172 and 181; whereas insert A2 contains a calculated charge of -5 and lacks an internal disulfide bond. The second region of alternative splicing (splice insert B, residues 298-305), unique to NL1, contains an $\mathrm{N}$-glycosylation consensus sequence at Asn303, shown to negatively regulate the $\beta$-neurexin association (14). Moreover, it was recently shown that NL1 also binds to $\alpha$-neurexins but only when lacking splice insert B or after

\footnotetext{
${ }^{1}$ Abbreviations: NL1, neuroligin-1; NL2, neuroligin-2; NL3, neuroligin-3; NL4, neuroligin-4; SPR, surface plasmon resonance; NX1 $\beta$, $\beta$-neurexin-1; RU, resonance units; GST, glutathione- $S$-transferase.
} 
enzymatic removal of the $\mathrm{N}$-linked carbohydrates at position N303 (15). The gene encoding NL3 has two cassettes of alternative splicing at position $\mathrm{A}$ : one is homologous with the NL1 insert, and the second is homologous with the insert found in NL2 (4). NL4 has thus far revealed no identified inserts (5).

The $\beta$-neurexin family is comprised of three genes each containing two sites of alternative splicing, defined sites 4 and 5 . The splice insert at site 5 is found in close proximity to the transmembrane domain, whereas the splice insert at site 4 is in the laminin-G (LG)-like domain (16). The threedimensional structure of the extracellular domain of $\beta$-neurexin-1 $(\mathrm{NX} 1 \beta)$ truncated upstream of site 5 has a structural fold typical of other LG-domain proteins (17). Association between the neurexins and neuroligins appears to be $\mathrm{Ca}^{2+}$ dependent and modulated by the 30 residue neurexin insert that can be alternatively spliced at site $4(4,18,19)$.

Alternative mRNA splicing is a widespread mechanism in eukaryotes that leads to developmental and tissue-specific expression of unique insertions and deletions within the encoding mRNA species. At the protein level, alternatively spliced sequences typically do not influence the global folding of the protein but introduce variation of superficial loops that result in altered function, such as ligand or protein association or catalytic activity $(20,21)$. At the cellular level, these changes translate into fine-tuning of recognition at synapses during development and plasticity in the central nervous system.

In this study, we employ surface plasmon resonance (SPR) and affinity chromatography to monitor directly the association of each NL subtype with two splice variants of NX1 $\beta$ to ascertain their binding specificities. The functional roles in recognition of the splice inserts of both neuroligins and $\beta$-neurexins become critical in this analysis. We show that the concerted events of gene selection, alternative splicing, and post-translational processing hierarchically regulate $\beta$-neurexin-neuroligin associations. These data enable us establish a rank order for binding affinities among various neuroligins and $\beta$-neurexins that should serve as a molecular basis for understanding the more complex in vivo interaction patterns of these two synaptic molecules.

\section{MATERIALS AND METHODS}

Plasmids and Mutagenesis. For SPR assays, the extracellular domain (residues 48-300) of the rat NX1 $\beta$ was fused to the $\mathrm{C}$-terminal end of a cleavable glutathione- $S$-transferase (GST) module described previously (22). Two NX1 $\beta$ isoforms, with and without splice insert 4 , were constructed and referred to as $\mathrm{NX} 1 \beta-3$ and $\mathrm{NX} 1 \beta-1$, respectively. The Ig-NX1 $\beta$ fusion proteins with and without splice insert 4 (Ig-NX1 $\beta$-3 and $\operatorname{Ig}-\mathrm{NX} 1 \beta-1$, respectively) used in the pulldown assays were described previously $(14,23)$.

cDNAs encoding rat NL1-NL4 were subcloned into a FLAG-tagged vector (Sigma, St. Louis, MO) for detection and purification (14). Briefly, the vector encodes an $\mathrm{N}$ terminal FLAG octapeptide, a linker peptide of 4-10 residues followed by the neuroligin sequences. Soluble species for all four neuroligins were constructed by introducing stop codons at Ile639, Phe616, Tyr640, and Ser620, generating the proteins NL1-638A 1 /B, NL2-615A, NL3-639, and NL4-619 respectively. The NL1-638A 1 /B construct contained splice inserts $A_{1}$ and $B$, and NL2-615A contained splice insert A, whereas NL3-639 and NL4-619 constructs did not contain a splice insert. For direct comparisons, NL1 was also engineered with splice insert $\mathrm{A}_{2}$ substituted (NL1$\left.638 \mathrm{~A}_{2} / \mathrm{B}\right)$, without splice insert A (NL1-638- $\left.\Delta \mathrm{A}\right)$, without splice insert B (NL1-638- $\triangle B$ ), and without both [NL1-638$\triangle(\mathrm{A} \& \mathrm{~B})]$. NL2 was also constructed devoid of splice insert A (NL2-615- $\triangle \mathrm{A}$ ) (upper panel in Figure 1).

Cell Culture and Transfections. HEK293 cells were maintained at $37{ }^{\circ} \mathrm{C}$ and $10 \% \mathrm{CO}_{2}$ in Dulbecco's modified Eagle's medium containing $10 \%$ fetal bovine serum and periodically tested to ensure the absence of mycoplasma contamination. Cells were transfected with the appropriate plasmids and selected by growth in G418 (Geneticin, Sigma) (14). After 2-3 weeks, surviving cells formed colonies suitable for clonal selection. The best producing clones were further expanded for large-scale production of soluble neuroligins.

Neuroligin and $\beta$-Neurexin Expression and Purification. The soluble NX1 $\beta$-GST fusion protein was affinity-purified from bacterial extract using Glutathione Sepharose 4B (Amersham Biosciences, Piscataway, NJ). To purify soluble neuroligins, cell-culture medium containing the soluble protein was passed over an M2 anti-FLAG-affinity column (Sigma) (14). Protein concentrations were estimated by a standard Bradford assay. To check the purity and absence of degradation products, proteins were separated on $10 \%$ sodium dodecyl sulfate-polyacrylamide gel electrophoresis (SDS-PAGE) gels and stained with Simply Blue Safestain (Invitrogen, Carlsbad, CA). For purification of the soluble Ig-NX1 $\beta$ fusion proteins, a similar protocol was used. However, protein A Sepharose 4 Fast Flow (Amersham Pharmacia Biotech AB, Sweden) was employed to bind the human-IgG portion of $\mathrm{NX} 1 \beta$ (14). After elution, proteins were concentrated and buffer-exchanged [10 $\mathrm{mM} \mathrm{N}-2$ hydroxyethylpiperazine- $N^{\prime}$-2-ethanesulfonic acid (Hepes) buffer at $\mathrm{pH} 7.4$ and $150 \mathrm{mM} \mathrm{NaCl}$.

Mass Spectrometry. Matrix-assisted laser desorption/ ionization time-of-flight (MALDI-TOF) mass spectrometry was performed on a PE Biosystems Voyager DE-STR instrument (Framingham, MA). Purified recombinant neuroligins at $1 \mathrm{mg} / \mathrm{mL}$ in $0.1 \%(\mathrm{v} / \mathrm{v})$ trifluoroacetic acid (TFA) were mixed $1: 1$ with a matrix of $10 \mathrm{mg} / \mathrm{mL}$ saturated sinapinic acid (3,5-dimethoxy-4-hydroxy-cinnamic acid) dissolved in $30 \%$ acetonitrile and $0.3 \%$ TFA ( $\mathrm{pH} 2.2$ ). Droplets $(1 \mu \mathrm{L})$ of neuroligin-matrix mixture, containing approximately 10 pmol of protein, were spotted and dried by slow evaporation. Mass spectra were collected using linear mode, and external calibration was performed using yeast enolase protein $(+1$ dimer and +1 and +2 monomer mass-to-charge species).

Sedimentation Analysis. Analytical ultracentrifugation was conducted in a Beckman/Coulter XL-I centrifuge using An60Ti and An50Ti rotors at UCSD and CAUMA. ${ }^{2}$ For equilibrium experiments, we centrifuged $125 \mu \mathrm{L}$ of protein samples [in nine combinations using optical densities (OD)

${ }^{2}$ UCSD, Department of Biochemistry at the University of CaliforniaSan Diego. Most of the experiments were performed with a similar machine at the Center for Analytical Ultracentrifugation of Macromolecular Assemblies (CAUMA, Department of Biochemistry at the University of Texas Health Science Center at San Antonio). 
[A] $[\mathrm{B}]$
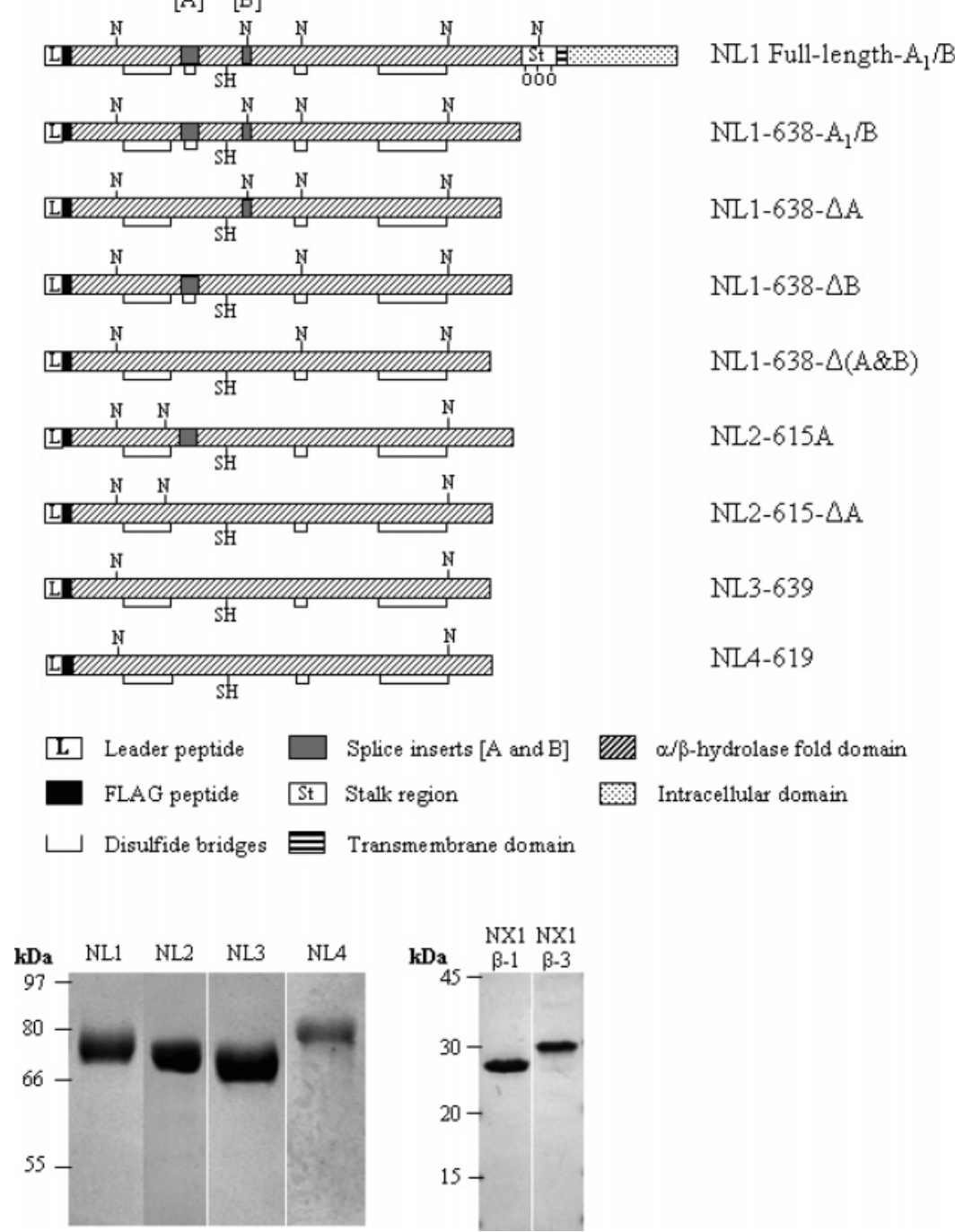

FIGURE 1: Schematic representation of the extracellular domains of the neuroligins. (Upper panel) Domain organization of the full-length recombinant NL1 is shown on top. The leader peptide is absent in the mature protein. $\mathrm{N}$ and $\mathrm{O}$, consensus sequences for $\mathrm{N}$ - and $\mathrm{O}$-linked glycosylation sites; SH, free cysteine. For NL1, disulfide bonds were assigned and glycosylation sites were identified by mass spectrometry (30). (Lower panel) Coomassie blue staining of purified neuroligins and $\beta$-neurexin. While neurexin contains a single $\mathrm{N}$-linked consensus sequence, it was expressed in bacteria not capable of oligosaccharide additions. Molecular masses of the various proteins are in agreement with MS-MALDI values reported in Table 1 . NL1, NL1-638- $\Delta$ (A\&B); NL2, NL2-615- $\Delta$ A; NL3, NL3-639; NL4, NL4-619. NX1 $\beta-1$ and NX1 $\beta-3$ refer to the cleaved GST fusion proteins.

of $0.3,0.5$, and 0.7 and monitoring at 215,230 , and 280 $\mathrm{nm}]$. All samples were run in $10 \mathrm{mM}$ sodium phosphate buffer at $\mathrm{pH} 7.4$, with $137 \mathrm{mM} \mathrm{NaCl}$ and $2.7 \mathrm{mM} \mathrm{KCl}$ (unless otherwise noted) at five rotor speeds, resulting in 45 conditions that were scanned at equilibrium. Extinction coefficients at multiple wavelengths were determined as described in ref 24 and were found to be $8.864 \times 10^{5}, 4.045$ $\times 10^{5}$, and $9.23 \times 10^{4}$ for NL1 at 215,230 , and $280 \mathrm{~nm}$, respectively, and $9.815 \times 10^{5}, 4.586 \times 10^{5}$, and $9.87 \times 10^{4}$ for NL4 at 215, 230, and $280 \mathrm{~nm}$, respectively. Column length was $\sim 3 \mathrm{~mm}$ for the $125 \mu \mathrm{L}$ of sample. Sedimentation equilibrium for neuroligins was conducted at $20{ }^{\circ} \mathrm{C}$ at the following speeds and times: $8.8 \mathrm{krpm}(44 \mathrm{~h}), 11.7 \mathrm{krpm}$ (26 h), $14 \mathrm{krpm}(17 \mathrm{~h}), 16 \mathrm{krpm}(11 \mathrm{~h})$, and $17.7 \mathrm{krpm}$ $(8 \mathrm{~h})$. Data at equilibrium were recorded in radial step mode with $0.001 \mathrm{~cm}$ stepsize setting with 20 replicate absorption measurements at each step. Equilibrium experiments where globally fitted to multiple models; the fitting statistics were obtained by performing Monte Carlo analysis. All sedimentation equilibrium and sedimentation velocity experiments were analyzed with the UltraScan software (25). For equilibrium analysis, data exceeding 0.9 OD were excluded from the fits.

Oligomeric states of NL1-NL4 were also investigated by sedimentation velocity in Hepes buffer at pH 7.4. NL1-638$\Delta$ (A\&B) $(500 \mu \mathrm{L}$ at $280 \mathrm{~nm}, \mathrm{OD}$ of $\sim 1.0)$ were centrifuged at $60000 \mathrm{rpm}$ and $20{ }^{\circ} \mathrm{C}$ in double-sector aluminum centerpieces using the Rayleigh interference optics of the Beckman Optima XL-I. Sedimentation coefficient distributions were determined by the enhanced van Holde-Weischet analysis (26). For homogeneous samples, molecular masses were estimated by fitting whole boundaries with finite element solutions of the Lamm equation $(27,28)$ as implemented in UltraScan. Partial specific volume, $\bar{v}$, of the $\beta$-neurexins and the neuroligins were calculated using the Sednterp software (29). Because the AChE-like domain of the neuroligins is N-linked glycosylated, Sednterp was used to calculate the contribution of the sugars to the buoyancy of the molecule using average values from ref 30 . Calculated $\bar{v}$ were 0.727 for NL1, 0.724 for NL2, 0.729 for NL3, 0.729 
Table 1: Molecular Masses of Truncated Neuroligins and Neurexins Measured by Sedimentation Equilibrium and Mass Spectrometry

\begin{tabular}{|c|c|c|c|c|c|c|}
\hline & NL1-638- $\Delta(A \& B)$ & NL2-615- $\Delta \mathrm{A}$ & NL3-639 & NL4-619 & NX1-b1 & NX1-b3 \\
\hline sequence-computed peptide $M_{\mathrm{r}},(\mathrm{kDa})$ & 65.5 & 63.1 & 65.9 & 66.1 & 24.8 & 28.3 \\
\hline$M_{\mathrm{r}}$, determined by sedimentation equilibrium $(\mathrm{kDa})$ & $150.8(75.4)^{a}$ & & & 151.3 & 24.1 & 27.7 \\
\hline$M_{\mathrm{r}}$, determined from mass spectrometry $(\mathrm{Da})$ & 71734 & 70022 & 69122 & 72665 & 24.8 & nd \\
\hline
\end{tabular}

${ }^{a}$ Monomer-dimer model, with $K_{\mathrm{d}}$ in a submicromolar concentration.

for NL4, 0.732 for free neurexin, 0.729 for the NL1/neurexin complex, and 0.729 for the NL4/neurexin complex.

Neuroligin/Neurexin Pulldown Experiments. Protein A Sepharose 4 fast-flow ( $50 \mu \mathrm{L})$ was incubated for $30 \mathrm{~min}$ at room temperature with $200 \mu \mathrm{g}$ of either Ig-NX1 $\beta-1$ or IgNX1 $\beta-3$ and washed extensively to remove unbound neurexin. The immobilized neurexins were then incubated for 10 min with $10 \mu \mathrm{g}$ of the soluble neuroligins: NL1-638- $\Delta$ (A\&B), NL2-615- $\triangle \mathrm{A}$, or NL3-639 in $100 \mu \mathrm{L}$ of $10 \mathrm{mM}$ Hepes buffer at $\mathrm{pH} 7.4,150 \mathrm{mM} \mathrm{NaCl}, 2 \mathrm{mM} \mathrm{CaCl}_{2}$, and $0.005 \%(\mathrm{v} / \mathrm{v})$ surfactant $\mathrm{P} 20$ at room temperature. The supernatant containing unbound neuroligin (flow through) was removed, and the resin was rinsed 3 times with $100 \mu \mathrm{L}$ of binding buffer (washes 1, 2, and 3). The neuroligins were then eluted with $10 \mathrm{mM}$ Hepes buffer at pH 7.4, $1 \mathrm{M} \mathrm{NaCl}$, $10 \mathrm{mM}$ ethylene glycol bis(2-aminoethyl ether)- $N, N, N^{\prime}, N^{\prime}$ tetraacetic acid (EGTA), and $0.05 \%(\mathrm{v} / \mathrm{v})$ surfactant P20 (elution buffer). The neurexins were eluted from protein $\mathrm{A}$ with $10 \mathrm{mM}$ glycine buffer at $\mathrm{pH} 1.8$. Fractions of $20 \mu \mathrm{L}$ were separated by SDS-PAGE electrophoresis and stained with Simply Blue Safestain to analyze the distribution of the unbound neuroligins.

SPR Analysis of the NL1-NX1 $\beta$ Complex. All binding experiments were done at $25^{\circ} \mathrm{C}$ in $10 \mathrm{mM}$ Hepes buffer at $\mathrm{pH} 7.4$ containing $150 \mathrm{mM} \mathrm{NaCl}, 2 \mathrm{mM} \mathrm{CaCl}_{2}$, and $0.005 \%$ $(\mathrm{v} / \mathrm{v})$ surfactant $\mathrm{P} 20$ on a BIAcore 3000 apparatus. NX1 $\beta$ was covalently bound to the carboxymethylated dextran matrix of a CM5 chip (BIAcore, Uppsala, Sweden) (31) to achieve between 1000 and 3500 resonance units (RU). To obtain specific NX1 $\beta$ binding, the first flow cell was mockcoupled with buffer only for real-time background subtraction. The neuroligins were injected in random order over the NX1 $\beta$ surfaces as a set of seven concentrations extending from 9000 to $12 \mathrm{nM}$ in 3-fold dilutions (unless otherwise noted) at a flow rate of $50 \mu \mathrm{L} / \mathrm{min}$ to minimize sample diffusion and mass transport limitations. After each injection, the binding surfaces were regenerated by injecting for $30 \mathrm{~s}$ a buffer containing $1 \mathrm{M} \mathrm{NaCl}$ and $5 \mathrm{mM}$ EGTA to chelate free $\mathrm{Ca}^{2+}$. To calculate the affinity of various neuroligins toward immobilized $\mathrm{NX} 1 \beta-1$, total binding at equilibrium was recorded. Steady-state binding signals were plotted as a function of the neuroligin concentration; plots were fit by nonlinear regression to calculate dissociation constants, $K_{\mathrm{d}}$.

\section{RESULTS}

Expression and Characterization of Soluble Neuroligins and Neurexins. To generate soluble protein suitable for SPR, analytical centrifugation, and mass spectrometry analyses, proteins were truncated at homologous positions just Cterminal to the $\mathrm{AChE}$ homologous domain, generating the proteins NL1-638A 1 /B, NL2-615A, NL3-639, and NL4-619 and their splice variants (upper panel in Figure 1). FLAGaffinity purification yielded homogeneous preparations virtually devoid of contaminant bands (lower panel in Figure 1).
Mass spectrometry analysis showed the molecular masses of the neuroligins to be compatible with the presence of processed N-linked oligosaccharides (Table 1).

NL1 was previously reported to form dimers in both truncated and full-length forms, implying that the sequence responsible for dimerization is in the extracellular domain $(14,32)$. To further characterize the oligomerization state of NL1-NL4 variants, we conducted sedimentation equilibrium experiments. For reversibly self-associating proteins, the oligomerization state is controlled by the concentration and the equilibrium dissociation constant, $K_{\mathrm{d}}$. To define optimally the $K_{\mathrm{d}}$ for a reversible self-association, a large concentration range is required. This is achieved by varying the loading concentration and the wavelength of the measurements. Therefore, using wavelengths of $215 \mathrm{~nm}$, the lowest neuroligin concentration that we measured was 13 $\mu \mathrm{g} / \mathrm{mL}$, corresponding to approximately $200 \mathrm{nM}$. On the basis of sedimentation equilibrium analyses over a wide range of protein concentrations and rotor speeds, all four neuroligins were determined to be extremely stable dimers virtually devoid of free monomer. Only for NL1, at the lowest concentration scans in the global fit, was it possible to detect traces of monomers, sufficient to estimate a $K_{\mathrm{d}}$ value (479 nM, 95\% confidence range from +99 to $-82 \mathrm{nM}$; monomer molecular weight of $75.4 \mathrm{kDa}, 95 \%$ confidence range from +1.07 to $-0.97 \mathrm{kDa}$ ), a value still within the concentration range of our experiment and in good agreement with our mass spectrometry determinations. This result indicates that under physiological conditions NL1 is present as a dimer. Global fits of the NL4 experiment were best-fit with a single ideal species model (molecular weight of 151.3 $\mathrm{kD}, 95 \%$ confidence interval from +0.66 to $-0.75 \mathrm{kD}$ ) (parts $\mathrm{A}$ and $\mathrm{B}$ of Figure 2). Sedimentation velocity experiments were done to characterize further the solution properties of NL1-NL4 and their interaction with NX1 $\beta$-1 (Figure 2C). The composition was evaluated on the basis of the shape of the van Holde-Weischet integral distribution plots (33). NL1-NL4 sedimented as single species systems, although a small amount of aggregation $(<10 \%)$ was apparent in NL1 and NL4. NL1-NL3 sedimented between 6.3 and $6.4 \mathrm{~s}$, while NL4 sedimented slightly faster at $6.8 \mathrm{~s}$, probably because of a combination of its higher molecular weight and a slightly more compact shape (Table 1 ). Free NX1 $\beta-1$ sedimented essentially as a single species with an $s$ value of $\sim$ 2.1. Molecular-weight determinations using whole boundary fitting indicated that $\mathrm{NX} 1 \beta-1$ sedimented as a monomer. In agreement with the equilibrium experiments, hydrodynamic experiments also confirmed that none of the neuroligins exists as free monomers at this concentration. When these results were compared with previous findings where NL1-638A1 was used for sedimentation equilibrium analysis (14), we conclude that the presence of splice inserts $\mathrm{A}$ and $\mathrm{B}$ do not influence the dimerization of the neuroligins. The formation of the dimer in the extracellular domain was also 

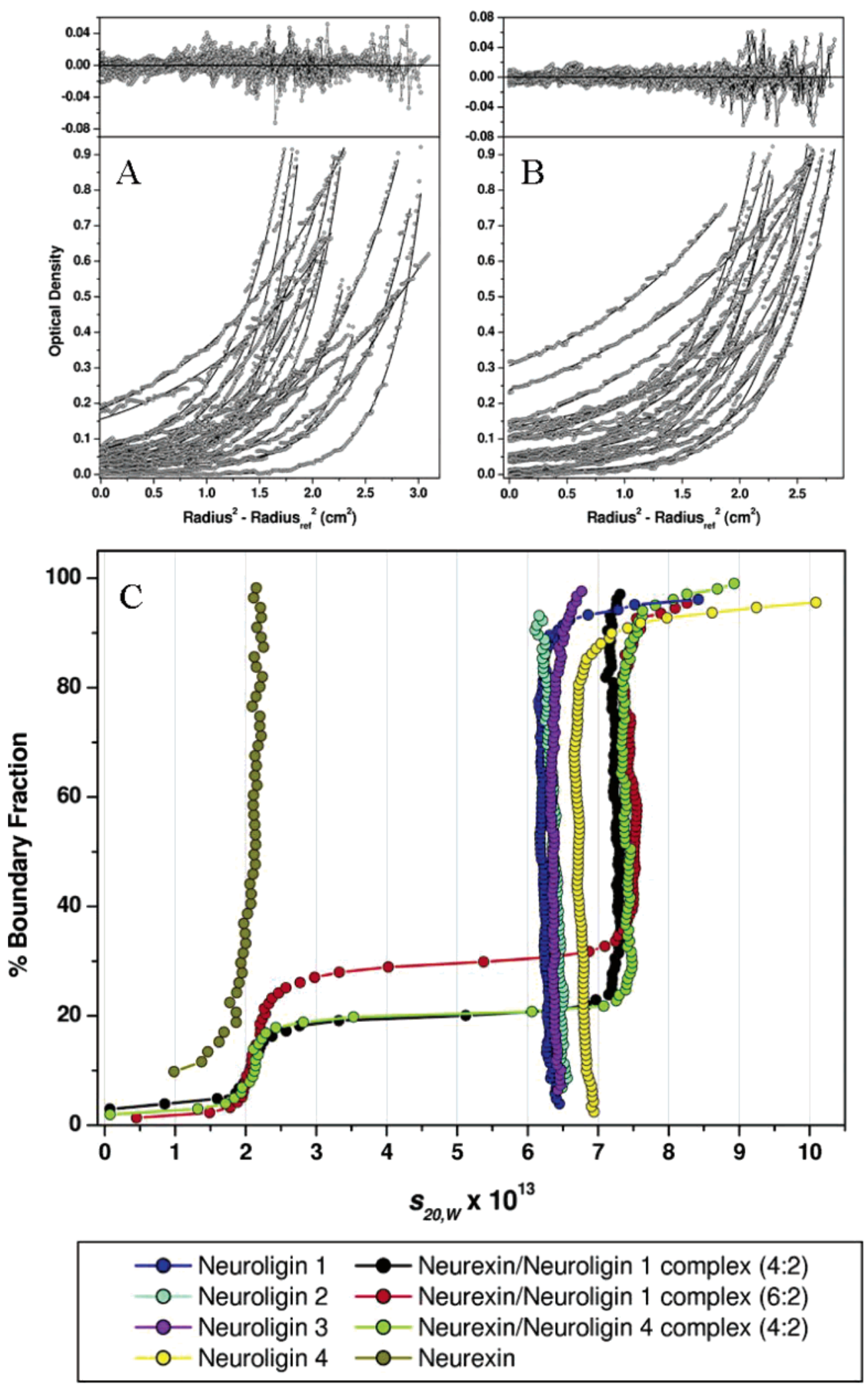

FIGURE 2: Global equilibrium analysis of NL1-NL4 and NX1 $\beta$. (A) NL4 was best-fit by a single ideal species model, resulting in a molecular weight in excellent agreement with the calculated dimeric molecular weight. (B) NL1 was best-fit with a monomer-dimer reversible self-association model, resulting in a monomer molecular weight in agreement with the monomeric molecular weight calculated by Sednterp. Shown here are the residuals of the fit (top section of the plot) and model ( - ) and experimental data points (gray circles) in the bottom section of the plot. The model matches the experimental data very well, and the residuals show a random, nonsystematic distribution about the mean. (C) G(s) distribution plots from the enhanced van Holde-Weischet analysis (26) of sedimentation velocity experiments performed on NX1 $\beta-1$, NL1-NL4, and NX1 $\beta-1 / N L 1$ and NL4 complexes. The NL1-NL4 sediment is shown as a single homogeneous species (blue, cyan, purple, and yellow, respectively). Free neurexin (brown) shows a homogeneous distribution that corresponds to monomeric conformation. Free monomeric neurexin is also evident in the mixtures of NL1 and NL4 with neurexin (black/red and green, respectively). A shift of the $s$ value of NL1 and NL4 by more than $15 \%$ to $\sim 7.5 \mathrm{~s}$ upon the addition of neurexin indicates complex formation. In the $4: 2$ sample, approximately $15 \%$ of the absorbance corresponds to free neurexin, while in the $6: 2$ sample about $29 \%$ of the neurexin is free. 
independent of the single unpaired Cys common to all of the neuroligins because its mutation to alanine in NL did not impair dimerization (data not shown).

Recent studies show that presynaptic clustering of the neurexins is necessary for stimulation of synaptogenic activity by NL1, but the stoichiometry of the neurexinneuroligin complex is thus far unknown (32). To further characterize the association of $\mathrm{NX} 1 \beta-1$ with neuroligins, we conducted sedimentation velocity experiments of NL1 and NL4 mixed with $\mathrm{NX} 1 \beta-1$ in the presence of $2 \mathrm{mM} \mathrm{Ca}^{2+}$. Velocity experiments of NL1 and NL4 combined with NX1 $\beta$-1 fit a sedimentation coefficient distribution consistent with a non-interacting two-component system (Figure 2C). Furthermore, mixing NL1 or NL4 with $\mathrm{NX} 1 \beta-1$ caused a significant increase in the value of the neuroligin peak from 6.5 to $\sim 7.5 \mathrm{~s}$. The sharp separation of free and complexed neurexin indicates the formation of a tight complex.

Because of the presence of a small amount of aggregate, fitting to a non-interacting two-component system did not allow for the extraction of exact molecular weights. Nonetheless, using a titration approach, it was possible to ascertain the stoichiometry of the association. A ratio of four NX1 $\beta-1$ molecules for each dimer unit of neuroligin (4:2 stoichiometry) yielded a second peak of $\sim 15 \%$ of the total absorbance, at $2.1 \mathrm{~s}$, which corresponds to free $\mathrm{NX} 1 \beta-1$. Increasing this ratio to $6: 2$, free $\mathrm{NX} 1 \beta$ accounted for $\sim 29.3 \%$ of the total absorbance. A doubling of the free NX1 $\beta-1$ indicates a 2:2 neuroligin-neurexin stoichiometry with NL1 because a smaller fractional increase of the $2.1 \mathrm{~s}$ peak $(25 \%)$ would be expected for a 1:2 stoichiometry. Furthermore, the excess of NX1 $\beta-1$ did not increase the sedimentation coefficient of the complex, indicating that full occupancy of the $\mathrm{NX} 1 \beta$ sites occurs when equimolar concentrations of neurexin and neuroligins are mixed. On the basis of the respective extinction coefficients of the free species and the NL1/ NX1 $\beta-1$ complex and from the non-interacting 2 species integral sedimentation coefficient distribution, we conclude that the NL1/NX1 $\beta-1$ association has a $K_{\mathrm{d}} \leq 200 \mathrm{nM}$ (the detection limit of the instrument for this extinction coefficient) and is consistent with a 2:2 stoichiometry. Identical results were achieved for NL4 (Figure 2C).

Neuroligin Family Members Exhibit Distinct Specificities for Different NXI $\beta$ Isoforms. Using column adsorption and elution parameters as well as cellular responses, a NX1 $\beta$ isoform containing a splice insert at position $4 \mathrm{did}$ not exhibit appreciable binding to the neuroligins $(3,4,18,19)$. Using buffers identical to the SPR analysis, with Ig-NX1 $\beta$ in a $20-$ fold excess over the neuroligin concentrations, we examine the association of different soluble neuroligins with Ig$\mathrm{NX} 1 \beta-1$ and Ig-NX1 $\beta-3$ by the fractional distribution of the bound and unbound neuroligin in pulldown experiments. Using Ig-NX1 $\beta-1$ as immobilized protein, we found that NL1-638- $\Delta(A \& B)$ was not detectable in the washes and incompletely eluted from the resin even when ethylenediaminetetraacetic acid (EDTA) was applied as an eluting agent (top left panel in Figure 4A). To achieve complete elution, Gly at $\mathrm{pH} 1.8$ is necessary (right panel in Figure 4B). By comparison, when Ig-NX1 $\beta$-3 was used, NL1-638- $\Delta$ (A\&B) was partially eluted during the washes and almost completely eluted by $\mathrm{Ca}^{2+}$ removal (top right panel in Figure 4A), indicating that the binding for both Ig-NX1 $\beta$ isoforms was specific. As previously reported, the apparent affinity of NL1 for Ig-NX1 $\beta-3$ was lower than the affinity for Ig-NX1 $\beta-1$. NL2 and NL3 appeared throughout all fractions, clearly showing their much lower affinity than $\mathrm{NL} 1$ for $\mathrm{NX} 1 \beta$. For this reason, with NL2 and NL3, we could not establish a definitive rank ordering of affinities for either $\mathrm{NX} 1 \beta$ forms by the pulldown assay (center and lower panels in Figure 4A and Figure 4B). To ensure that nonspecific binding was absent, Protein A-Sepharose without NX1 was used, demonstrating that no NL1 binding could be detected (left panel in Figure 4B).

SPR Quantification of the Affinity of Neuroligins for NXI $\beta$ 1 . We used SPR to quantify more precisely the association between $\mathrm{NX} 1 \beta-1$ and the four soluble neuroligins. NL1 contains two sites of alternative splicing, A and B, (4) whereas NL2 and NL3 only contain splice insert A. The frame of reference used to compare the binding activity of the individual neuroligins was the sequence encoded by the invariant exons devoid of both splice inserts, A and B. Hence, NL1 [NL1-638- $\Delta(A \& B)]$ was included in each experiment. The specific activity of NL1-638- $\Delta$ (A\&B) was calculated as RU generated using $1 \mu \mathrm{M}$ neuroligin protein associated with $1000 \mathrm{RU}$ of immobilized NX1 $\beta-1$. Using data from six independent experiments, the specific binding activity was calculated to be $1511 \pm 233(\mathrm{SE}) \mathrm{RU} / \mu \mathrm{M}$ NL1 (data not shown).

Previously, only the NL1 binding to NX1 $\beta-1$ was characterized by SPR (14). To compare the binding of NL2NL4 to NL1, each neuroligin was injected in multiple concentrations over the NX1 $\beta-1$ surface and the apparent affinity was compared to NL1 (Figure 3A). Because NL2-615A showed virtually no binding for NX1 $\beta-1$ at the concentrations typically used, high concentrations of injected samples (up to $40 \mu \mathrm{M})$ and high densities of immobilized NX1 $\beta-1$ on the chip surface were required to generate a respectable signal above the noise of the instrument. Owing to the large differences in affinity and apparent rates of association of the various neuroligins, affinities were estimated from SPR signals achieved at equilibrium during continuous neuroligin injection as a function of the neuroligin concentration (Figure 3B). Remarkably, the apparent affinity of NL2-615A was $\sim 300$-fold lower than the affinity of NL1-638- $\Delta$ (A\&B) for the same $\beta$-neurexin (Figure 3B). NL3-639 and NL4-619 displayed a binding affinity that appeared to be $\sim 60$ - and $\sim 4$.5-fold lower than NL1-638- $\Delta(\mathrm{A} \& \mathrm{~B})$, respectively.

Because measurements of NL association are continuous and are made in real time, comparative rates of association and dissociation can be estimated. Dissociation rates are reflected in the wash-out curves, and except for small tailing on some of the profiles, the data can be calculated as a firstorder process, where $\mathrm{dRU} / \mathrm{d} t=k_{-1}(\mathrm{RU})$. In general, the rates of dissociation of the neuroligins parallel their respective dissociation constants, where NL1-638- $\Delta(\mathrm{A} \& \mathrm{~B})$ has a dissociation rate of $\sim 0.9 \mathrm{~min}^{-1}$, NL4-619 is $7 \mathrm{~min}^{-1}$, and NL2 and NL3 are too fast $\left(>25 \mathrm{~min}^{-1}\right)$ to measure. For association, the bimolecular rate constant, $k_{1}$, can be calculated from the equation, $k_{\mathrm{obs}}=k_{1}[\mathrm{NL}]+k_{-1}$. Only in the case of NL1$638-\Delta(\mathrm{A} \& \mathrm{~B})$ do we approach saturation of the neurexin immobilized on the chip.

Effect of Splice Insert 4 of NXI $\beta$ on the Neuroligin Association. To quantitate the influence of splice insert 4 in NX1 $\beta$ on the association with NL1, equivalent molar quantities of $\mathrm{NX} 1 \beta-1$ and $\mathrm{NX} 1 \beta-3$ were immobilized and 

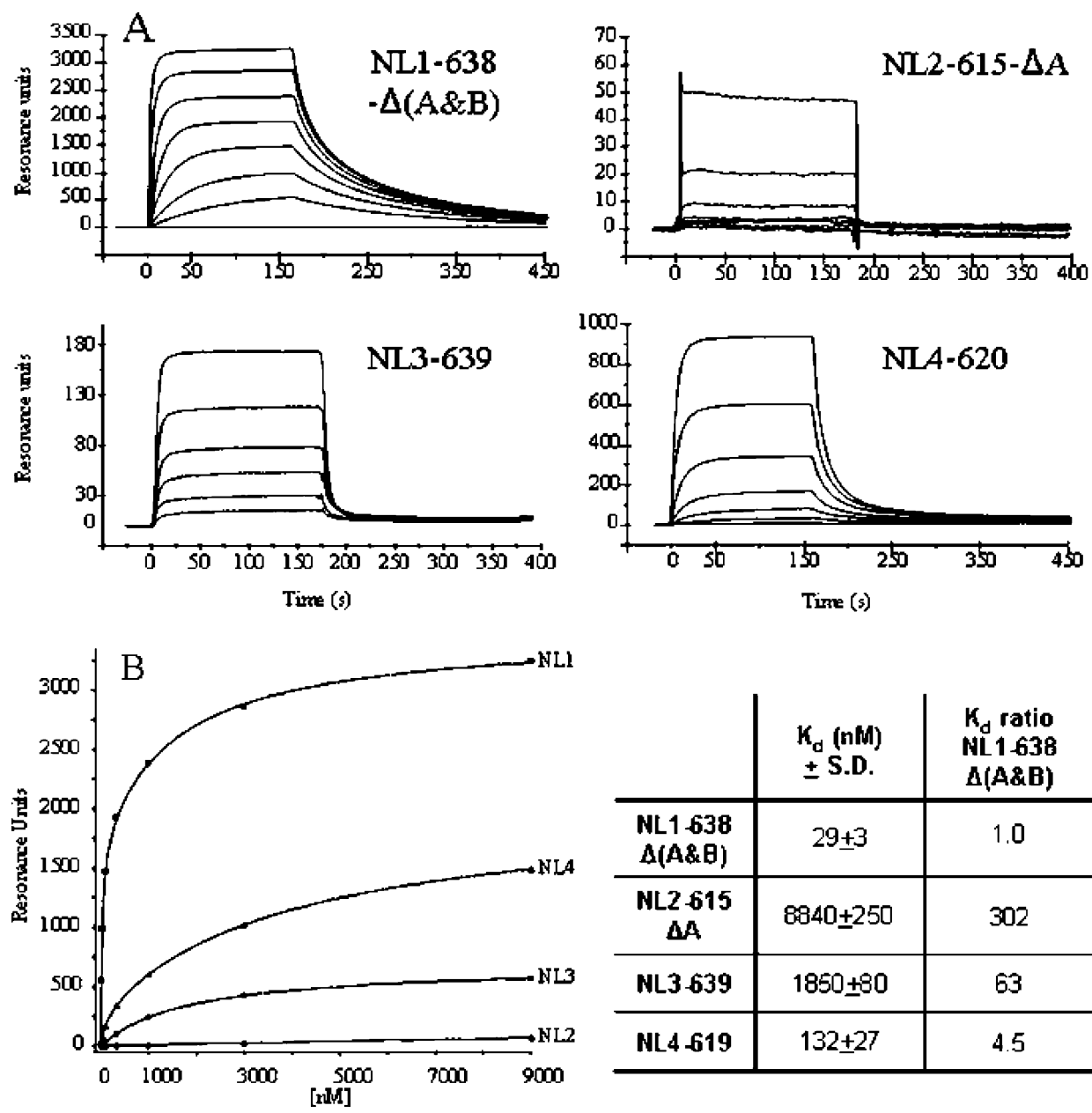

\begin{tabular}{c|c|c} 
& $\begin{array}{c}K_{\mathrm{d}} \text { (nM) } \\
\pm \text { S.D. }\end{array}$ & $\begin{array}{c}K_{d} \text { ratio } \\
\text { NL1 638 } \\
\Delta(\mathbf{A \& B})\end{array}$ \\
\hline $\begin{array}{c}\text { NL1 638 } \\
\Delta(\mathbf{A \& B})\end{array}$ & $29 \pm 3$ & 1.0 \\
\hline $\begin{array}{c}\text { NL2 .615 } \\
\Delta A\end{array}$ & $8840 \pm 250$ & 302 \\
\hline NL3 639 & $1850 \pm 80$ & 63 \\
\hline NL4 -619 & $132 \pm 27$ & 4.5 \\
\hline
\end{tabular}

FIGURE 3: SPR analysis of the neuroligins binding to NX1 $\beta$-1. (A) NL1-NL4, devoid of splice inserts, were injected over immobilized $\mathrm{NX} 1 \beta$ - 1 for approximately $180 \mathrm{~s}$ followed by a wash interval of $300 \mathrm{~s}$ with running buffer alone. The sensorgrams demonstrate a concentrationdependent association, as anticipated for a bimolecular association. Concentrations of injected proteins for each sensorgram are given below as two numbers: the first is the highest injected concentration (in nanomolar), and the second is the dilution factor, either 2-fold $(2 \times)$ or 3 -fold $(3 \times)$, that relates successive injections. NL1-638- $\Delta$ (A\&B) (9000; $3 \times$ and buffer only), NL2-615- $\Delta$ A (9000; $3 \times)$, NL3-639 $(10000 ; 2 \times)$, and NL4-619 (3000; $3 \times$ and buffer only). (B) Maximum binding measured at steady state during neuroligin injection was plotted as a function of the neuroligin concentration (left panel). The curves were fitted with a nonlinear regression, giving the dissociation constants $K_{\mathrm{d}}$ and the ratio of $K_{\mathrm{d}}$ values relative to NL1-638- $\Delta$ (A\&B) (right panel).

NL1-638- $\Delta(\mathrm{A} \& \mathrm{~B})$ was injected at multiple concentrations. A blank flow channel was used to generate reference data. Using this protocol, the same sample would sequentially run through the blank and both $\mathrm{NX} 1 \beta-1$ and $\mathrm{NX} 1 \beta-3$ flow channels, generating a signal corresponding to the affinity for each NX1 $\beta$ isoform. Given the geometry of the flow channels and the density of the adsorbed phase in the BIAcore 3000, progressive sample depletion should not occur among sequential flow channels. To calculate the relative affinities, maximum binding of the same nonsaturating concentration was compared in each condition. NL1 bound both neurexin isoforms, with a $2.1 \pm 0.45$-fold higher affinity for the NX1 $\beta-1$ isoform (Figure 5), indicating that splice site 4 in NX1 $\beta$ did not completely abolish NL1 binding. To ascertain whether splice insert 4 discriminates differentially glycosylated neuroligin forms, PNGase-F-treated NL1 was also used. PNGase-treated NL1 showed a faster SDS-PAGE migration than the untreated sample but displayed the same relative affinities for both $\mathrm{NX} 1 \beta-1$ and $\mathrm{NX} 1 \beta-3$ (data not shown and ref 14).

Because various members of the NL family showed large differences in association with $\mathrm{NX} 1 \beta-1$, we also sought to establish the relative selectivity of the individual neuroligins toward the two NX1 $\beta$ isoforms. NL2-NL4 were injected at 3-fold steps in concentration, and the same nonsaturating concentration was compared in each condition for both immobilized NX1 $\beta-1$ and $\mathrm{NX} 1 \beta-3$. Although to different extents, NL2-NL4 surprisingly displayed a slight preference for NX1 $\beta-3$ over NX1 $\beta-1$, thus these neuroligins have a rank ordering of affinities opposite to that of NL1 (Figure 6). These data indicate that splice insert 4 is not generally inhibitory to neuroligin association; rather, it appears to alter the rank order of selectivity for different neuroligins. Maximum binding of the same nonsaturating concentration from each individual isoform was used to plot the relative affinity (Figure 6).

Removal of NL1 Splice Insert A Slightly Decreases NXI $\beta-1$ Binding. NL1 and NL3 splice insert A is a 20 residue loop that exists in two distinct sequences: $A_{1}$ and $A_{2} . A_{1}$ contains a disulfide bond and carries nine positively charged residues (30); $\mathrm{A}_{2}$ is homologous to the splice insert A of NL2, lacks the disulfide loop, and carries seven negatively charged residues (4) (Figure 7A). Both splice insert A cassettes are highly charged and, thus, are likely to be solvent-exposed to the surface of the AChE-like domain. The lack of splice insert A decreased NL1-638 affinity for NX1 $\beta-1$ less than 

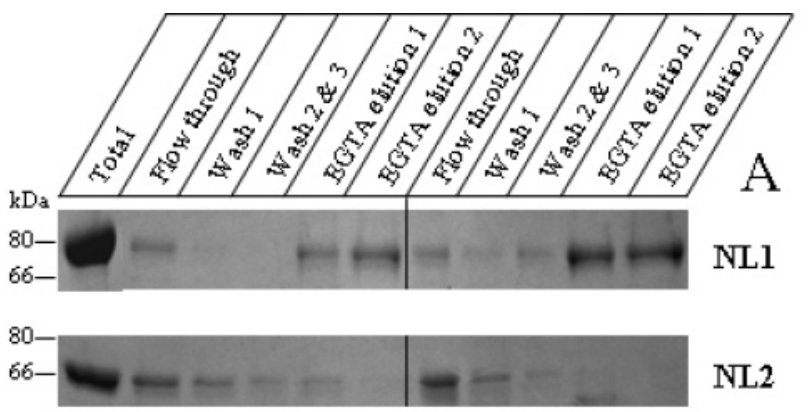

NL2

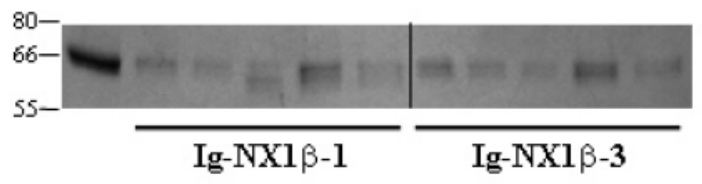

NL3

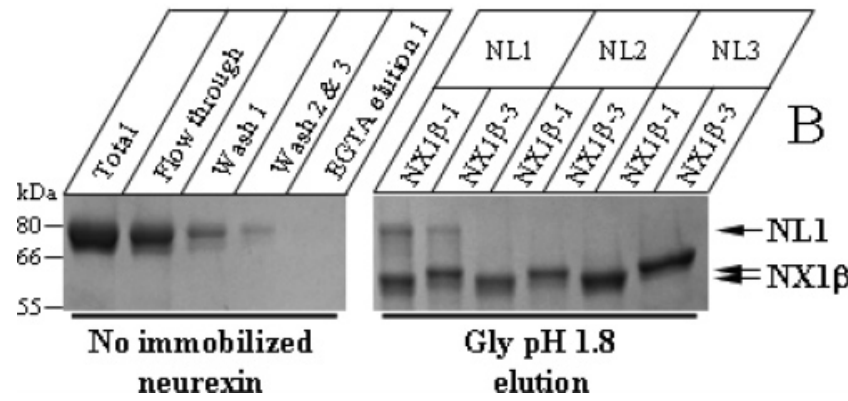

FIGURE 4: Affinity chromatography of NL1-NL3 binding to immobilized Ig-fusion NX1 $\beta$ with or without splice insert 4. (A) Purified recombinant Ig-NX1 $\beta$ splice variants immobilized on protein A-Sepharose and employed in pulldown assays with purified neuroligins lacking both splice inserts. Wash 2 and 3 results from the pooling of second and third washes. (B) (Left panel) Amount of nonspecific binding when no Ig-NX1 $\beta$ was immobilized on protein $\mathrm{A}$ is shown. (Right panel) Collected fractions after low $\mathrm{pH}$ elution. It is possible to distinguish $\mathrm{NX} 1 \beta-3$ from $\mathrm{NX} 1 \beta-1$ by the lower electrophoretic mobility because of the presence of the splice insert 4. All panels represent Coomassie blue staining of the eluted fractions.

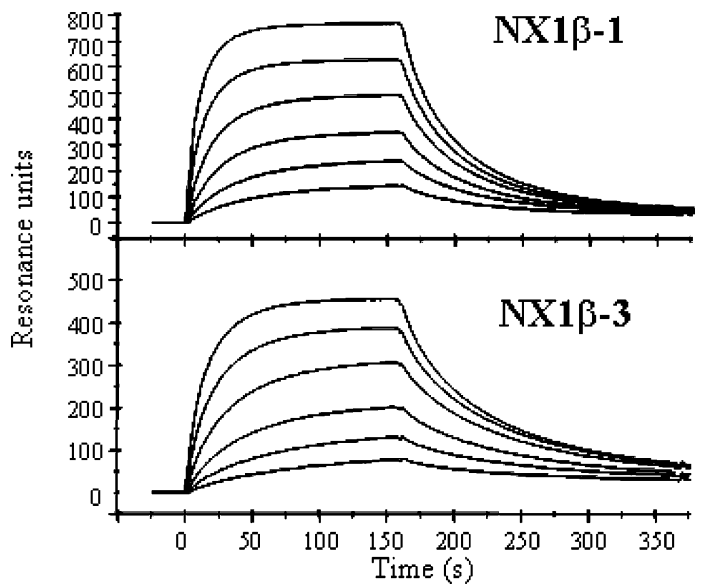

FIGURE 5: SPR analysis of NL1-638- $\Delta$ (A\&B) binding to NX1 $\beta-1$ and NX1 $\beta-3$. GST-cleaved NX1 $\beta-1$ and $N X 1 \beta-3$ were immobilized in equimolar amounts in two flow channels arranged in series. To compare the NL1 signal generated by the two NX1 $\beta$ isoforms, NL1 was injected for approximately $160 \mathrm{~s}$ followed by a decay interval of $200 \mathrm{~s}$. NL1 concentrations started at $1 \mu \mathrm{M}$ and were injected in random order in 2 -fold dilutions. Note that the amount of signal generated by the binding with $\mathrm{NX} 1 \beta-3$ is specific and, for each concentration, equals $\sim 50 \%$ of the signal produced by $\mathrm{NX} 1 \beta-1$.

2-fold. A similar reduction in affinity was obtained when splice insert $A_{2}$ was inserted in place of $A_{1}$. In NL2, deletion of splice insert A did not influence the NX $\beta 1$ association significantly, indicating that splice insert A plays a minimal role in these neurexin/neuroligin associations (Table 2).

Deletion of NL1 Splice Insert B Dramatically Increases $N X 1 \beta$ Binding. The eight residues composing the alternatively splice insert B are unique to NL1; this region was shown to carry an $\mathrm{N}$-linked sialylated oligosaccharide with a complex, tetraantennary chain at Asn303 (Figure 7B) (30) that partially inhibits in the association between NL1 and both $\mathrm{NX} 1 \alpha$ and $\mathrm{NX} 1 \beta(14,15)$. To study further the determinants of the insert on the $\mathrm{NX} 1 \beta-1$ association, we used as reference protein NL1-638A 1 , the isoform carrying both splice inserts. We first mutated Asn303 to Asp303 to mimic the effect of the PNGase F enzymatic treatment. As anticipated, the N303D-NL1-638A $/$ B bound NX1 $\beta-1$ with a $2.3 \pm 0.5$-fold higher affinity than $\mathrm{NL} 1-638 \mathrm{~A}_{1} / \mathrm{B}$ wild type, consistent with the demonstrated inhibitory effect of the glycosylation processing at this position (14).

We next removed the entire splice insert B and measured NX1 $\beta$ - 1 association of this NL1 isoform. Removal of the eight residue loop in NL1 led to a $9.2 \pm 3.5$-fold increase in affinity with respect to the wild-type protein, indicating that splice insert B exerts a strong inhibitory influence on the NX1 $\beta$-1 binding (Table 2). Interestingly, removal of both NL1 splice insert A and splice insert B increased the NX1 $\beta$-1 affinity $5.9 \pm 2.2$-fold, indicating that the two inserts independently influence the association and may partially offset each other (Table 2).

Removal of the eight residue loop brings in apposition two charged amino acids, Glu297 and Lys306. Because the neurexin-neuroligin association was previously shown to be electrostatically driven (14), the two charged amino acids could represent major binding determinants. To study the binding mechanism through the role of the charged amino acids, NL1-638 $A_{1}-\Delta B$ was used to make alanine mutations of either one or both residues flanking the splice insert. Alanine mutation of both residues reduced the affinity $\sim 5$ fold, yielding a value comparable to that found with the splice insert intact. The marked binding increase caused by the removal of splice insert $B$, along with the subsequent reduction of binding upon the mutation of the two flanking residues, suggested a mechanism by which a focal point of the neuroligin surface binding for $\beta$-neurexin is in the vicinity of this sequence containing the alternative splice region $\mathrm{B}$ (Table 2).

\section{DISCUSSION}

The multiple genes encoding the $\beta$-neurexins and neuroligins produce an even greater variety of gene products through alternative splicing and post-translational modifications of the attached oligosaccharide. We characterize here the oligomeric state of the extracellular domain of NL1NL4, describe the binding specificity among different neuroligins and $\beta$-neurexins, and define the role that different splice inserts in both families of proteins play in the affinity and specificity of the heterologous association. The multiplicity of products with different affinities reveals that an intricate recognition code exists among different neuroligins and $\beta$-neurexins.

SPR provides a more quantitative approach toward measuring protein-protein interactions in real time, kinetically 

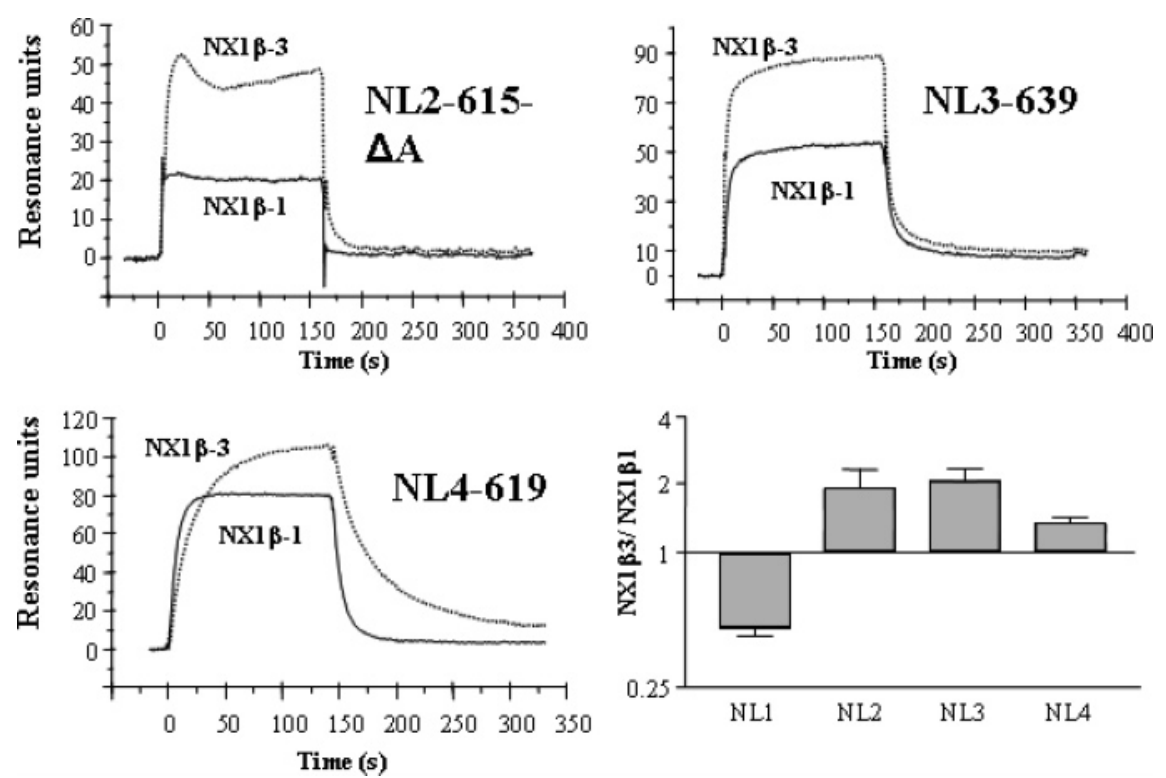

FIGURE 6: SPR analysis of NL2-NL4 binding to NX1 $\beta-1$ and NX1 $\beta-3$. Different neuroligins were injected over immobilized NX1 $\beta-1$ and NX1 $\beta$-3 as described in Figure 5. A single nonsaturating curve for each injection series was chosen to illustrate the neuroligin specificity for the two $\mathrm{NX} 1 \beta$ isoforms. The bar graph illustrates the ratio between the signals generated from $\mathrm{NX} 1 \beta-1$ versus $\mathrm{NX} 1 \beta-3$ among various neuroligins. Note that, whereas NL1 has a higher affinity for NX1 $\beta-1$, NL2-NL4 have a higher affinity for the NX1 $\beta$-3 form.
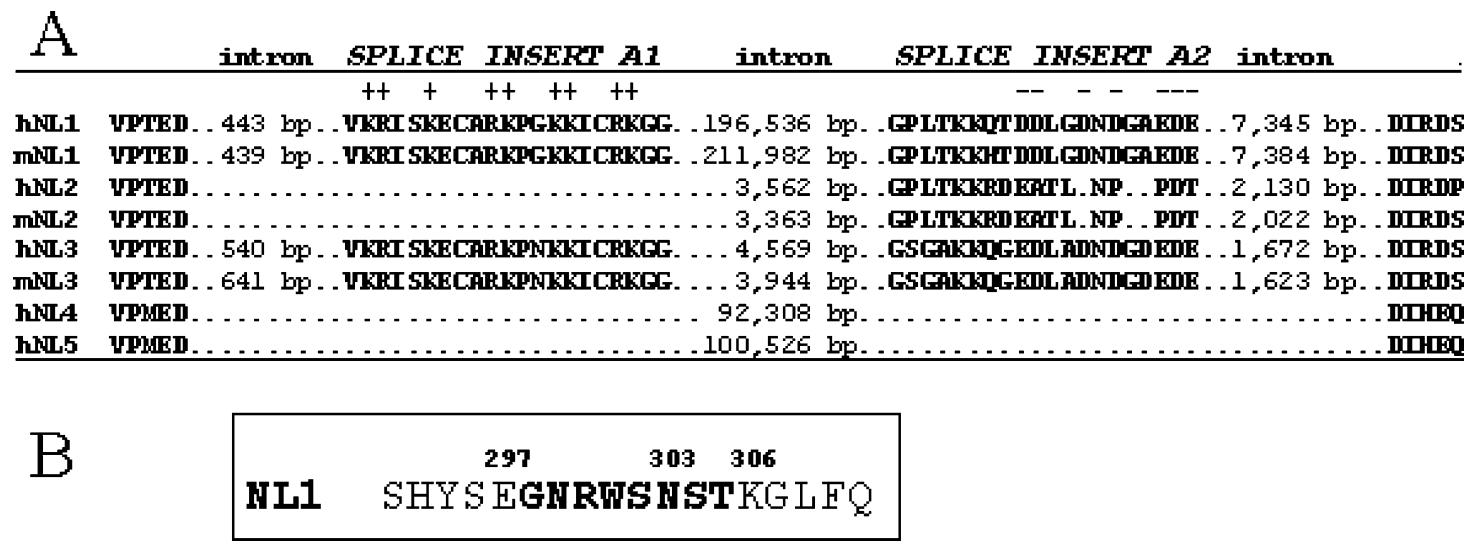

FIGURE 7: Genomic structure of the alternatively spliced insert A in neuroligins and sequences of the alternative inserts. (A) NL1 and NL3 show inserts $A_{1}$ and $A_{2}$ with close but not identical sequences. Note also the complete divergence between the $A_{1}$ and $A_{2}$ sequences. (B) Sequence of the splice insert B of NL1 flanked by five residues on each side. Numbering above the sequence denotes mutated residues cited in the text and in Table 2.

Table 2: Selectivity of NL1 and NL2 Splice Variants and Mutants for $\mathrm{NX} 1 \beta^{a}$

\begin{tabular}{|c|c|}
\hline & fold of wild type ${ }^{b}$ \\
\hline NL2-615A wild type & 1 \\
\hline NL2-615- $\Delta \mathbf{A}$ & $1.05 \pm 0.1$ \\
\hline NL1-638A 1 (wild type) & 1 \\
\hline NL1-638- $\Delta \mathbf{A}$ & $0.55 \pm 0.2$ \\
\hline NL1-638A 2 & $0.64 \pm 0.3$ \\
\hline NL1-638A $1-\Delta \mathbf{B}$ & $9.22 \pm 3.5$ \\
\hline NL1-638- $\Delta(\mathbf{A} \& \mathbf{B})$ & $5.96 \pm 2.2$ \\
\hline NL1-638A $1-\Delta \mathbf{B}-\mathbf{E 2 9 7 A} / \mathbf{K 3 0 6 A}$ & $2.13 \pm 0.3$ \\
\hline $\mathrm{NL} 1-638 \mathrm{~A}_{1}-\mathrm{N} 303 \mathrm{D}$ & $2.33 \pm 0.5$ \\
\hline
\end{tabular}

${ }^{a}$ The upper portion of the table shows the relative affinity between NL2-615A (referred as the wild type) and the splice alternative devoid of the insert at position A. The lower portion of the table shows the relative affinity among the five possible splice alternatives of NL1638 and two related mutants. ${ }^{b} \mathrm{~A}_{1}$ and $\mathrm{A}_{2}$ specify the presence of the two alternative inserts. $\Delta \mathrm{A}$ and $\Delta \mathrm{B}$ refer to the cDNAs devoid of the respective inserts.

and at equilibrium. Achieving accurate measurements relies on the initial purification and characterization of the two proteins. In vitro $\beta$-neurexin-neuroligin interactions are altered by the ionic strength of the buffer and require $\mathrm{Ca}^{2+}$ at concentrations similar to those in the extracellular environment $(4,14,18)$. We were able to demonstrate, with a standard error of $15 \%$ for the bound NL1 signal among independent experiments, that precision is sufficient for the quantitation of bound species and estimating dissociation constants. Reversing the phase orientation for the partnering proteins also yielded the same rank order of affinities for the complexes but with less precision and reproducibility when neuroligin is the tethered protein (see the Supporting Information).

Analytical ultracentrifugation established that the proteins used for SPR experiments were substantially homogeneous when associating with the detection surface. By comparison, pulldown and cell-based assays are limited in their quantitative end points, time resolution, and flexibility in adjusting experimental parameters.

The individual neuroligins have high amino acid sequence identities $(\sim 70 \%)$ in their extracellular domains. Nevertheless, divergent amino acids are the main determinants of 
$\beta$-neurexin binding affinity, spanning over 2 orders of magnitude. The high affinity that only NL1 shows for $\beta$-neurexin explains why NL1 was first isolated by affinity chromatography with $\beta$-neurexin as the immobilized phase (18). In addition, the recent identification of NL2 at inhibitory synapses $(11,12)$ and outside the central nervous system (10) suggests that neuroligins may have selective partners within the neurexin family. Consistent with these findings, we found that at the molecular level NL2 is functionally different from NL1, NL3, and NL4. However, in several cellbased assays, NL1 and NL2 displayed comparable activity $(3,4,12)$. NL3-R471C, a mutant that is characterized by defective processing, export to the cell membrane, and low $\beta$-neurexin affinity $(22,34)$, is able to stimulate synaptogenesis, albeit at a lower level compared to the wild-type protein (13). These in vivo data suggest that the inherent plasticity of the cellular environment, in conjunction with enhanced expression, could minimize differences in affinity and cellular localization that exist at the molecular level.

The three-dimensional structure of a $\beta$-neurexin module indicates that splice insert 4 is located in the long loop connecting $\beta$ strands 10 and 11 . Structural predictions suggest that the 30 amino acid long insert can form two helices that likely alter the overall secondary structure of the LG domain (17). Monitoring association by the more sensitive SPR technology demonstrates that the presence of splice insert 4 in $\beta$-neurexins does not abolish the binding of NL1. Moreover, the presence of the 30 amino acid insert slightly increased the binding specificity for other neuroligins, indicating that the inhibitory role of splice insert 4 might be directed solely toward high-affinity binding with NL1, therein altering a rank order of selectivity for the neuroligins. The extent to which these binding differences alter the in vivo function of the neuroligin/ $\beta$-neurexin association is just starting to emerge (35); however, these results establish that the primary sequence of the neuroligins is a primary determinant for the affinity for $\mathrm{NX} 1 \beta$.

The inhibitory role of the oligosaccharide carried by splice insert B was extensively studied in both $\alpha$ - and $\beta$-neurexins $(14,15)$. We now establish that, with NL1, a much larger increase in affinity for $\beta$-neurexin results upon the complete removal of the eight residue insert. When these data are taken together, they show a two-step, post-transcriptional mechanism that could be specifically modulated by cell type, where the insertion of the segment encoded by the alternatively spliced exon and subsequent post-translational processing of the N-linked glycosylation of the loop control both $\alpha$ and $\beta$-neurexin affinities. In addition, the splicing options afforded by the $\alpha$ - and $\beta$-neurexins in combination with neurexin and neuroligin gene selection provide both selectivity and diversity in the individual protein interactions necessary for development and plasticity.

Intronic gaps of considerable length flank the A insert of NL1. Recent studies on splicing of vertebrate proteins suggest that intron length influences alternative splicing efficiencies and patterns by enabling trans-acting factors to control tissuespecific protein expression (36).

Building upon the neuroligin homology model for AChE (37, 38), our study provides additional details on the determinants of the $\beta$-neurexin/neuroligin interaction. The formation of NL1 dimers, presumably stabilized by a four helix bundle between monomers $(14,32)$, provides the basis to model the $\beta$-neurexin association, consistent with the biochemical and hydrodynamic data presented here. Inserted peptides encoded by splice inserts A and B are found close to each other in the three-dimensional structure, whereby both could contact the surface of a single neurexin molecule. However, these splice inserts are well-removed from Arg473 (22), suggesting that the 473 position could influence neuroligin association by allosterically modifying the overall subunit conformation or by neurexin crossing the subunit interface to interact with both subunits in the neuroligin dimer. In either arrangement, the 2:2 stoichiometry prevails and each binding surface could directly involve the region flanking and encompassing splice site B and possibly a region close to $\operatorname{Arg} 473$ (22). Hence, the intrinsic dimerization capacity of the neuroligins, along with their capacity to associate with two neurexin molecules, provides the extracellular framework for the clustering of these molecules. Neurexin and neuroligin both contain PDZ-binding motifs (16) on their cytoplasmic domains that, in turn, enable the cytoplasmic association of the respective adhesion molecules with PDZ containing molecules at the pre- and postsynaptic surfaces.

Genetic studies involving autistic patients have revealed specific chromosomal mutations that coincide with the location of NL1 and NL2 genes $(39,40)$. Recent studies reported that a single missense mutation of NL3 and several other chromosomal deletion or point mutations of the NL4 gene were found in siblings with autism spectral disorders and mental retardation $(41-45)$. Because these genetic data strongly link the neuroligins and autism spectral disorders, they illustrate the pivotal importance of understanding stoichiometry and the surface of the association of the gene products to unravel the full adhesive function of these synaptic molecules $(22,46)$. Moreover, the fidelity of the sequence conservation across species and within members of the neuroligin and neurexin gene families, the rank ordering of affinities between partnering molecules, and their common mode of attachment to membranes support the concept of a multifaceted code for association between preand postsynaptic partnering proteins.

\section{ACKNOWLEDGMENT}

We thank Dr. Sergio Gloor at the Swiss Federal Institute of Technology (Zurich, Switzerland) for the human NL4 construct.

\section{SUPPORTING INFORMATION AVAILABLE}

SPR binding strategy and related controls. This material is available free of charge via the Internet at http:// pubs.acs.org.

\section{REFERENCES}

1. Shapiro, L., and Colman, D. R. (1999) The diversity of cadherins and implications for a synaptic adhesive code in the CNS, Neuron 23, 427-430.

2. Biederer, T., Sara, Y., Mozhayeva, M., Atasoy, D., Liu, X., Kavalali, E. T., and Sudhof, T. C. (2002) SynCAM, a synaptic adhesion molecule that drives synapse assembly, Science 297, 1525-1531.

3. Scheiffele, P., Fan, J., Choih, J., Fetter, R., and Serafini, T. (2000) Neuroligin expressed in nonneuronal cells triggers presynaptic development in contacting axons, Cell 10, 657-669. 
4. Ichtchenko, K., Nguyen, T., and Sudhof, T. C. (1996) Structures, alternative splicing, and neurexin binding of multiple neuroligins, J. Biol. Chem. 27, 2676-2682.

5. Bolliger, M. F., Frei, K., Winterhalter, K. H., and Gloor, S. M. (2001) Identification of a novel neuroligin in humans which binds to PSD-95 and has a widespread expression, Biochem. J. 356, $581-588$

6. Song, J. Y., Ichtchenko, K., Sudhof, T. C., and Brose, N. (1999) Neuroligin 1 is a postsynaptic cell-adhesion molecule of excitatory synapses, Proc. Natl. Acad. Sci. U.S.A. 96, 1100-1105.

7. Philibert, R. A., Winfield, S. L., Sandhu, H. K., Martin, B. M., and Ginns, E. I. (2000) The structure and expression of the human neuroligin-3 gene, Gene 246, 303-310.

8. Gilbert, M., Smith, J., Roskams, A. J., and Auld, V. J. (2001) Neuroligin 3 is a vertebrate gliotactin expressed in the olfactory ensheathing glia, a growth-promoting class of macroglia, Glia 34, $151-164$.

9. Ullrich, B., Ushkaryov, Y. A., and Sudhof, T. C. (1995) Cartography of neurexins: More than 1000 isoforms generated by alternative splicing and expressed in distinct subsets of neurons, Neuron 14, 497-507.

10. Kang, H. S., Lee, C. K., Kim, J. R., Yu, S. J., Kang, S. G., Moon, D. H., Lee, C. H., and Kim, D. K. (2005) Gene expression analysis of the pro-oestrous-stage rat uterus reveals neuroligin 2 as a novel steroid-regulated gene, Reprod., Fertil. Dev. 16, 763-772.

11. Varoqueaux, F., Jamain, S., and Brose, N. (2004) Neuroligin 2 is exclusively localized to inhibitory synapses, Eur. J. Cell Biol. 83, 449-456.

12. Graf, E. R., Zhang, X., Jin, S. X., Linhoff, M. W., and Craig, A. M. (2004) Neurexins induce differentiation of GABA and glutamate postsynaptic specializations via neuroligins, Cell. 119, 1013-1026.

13. Chubykin, A. A., Liu, X., Comoletti, D., Tsigelny, I., Taylor, P., and Südhof, T. C. (2005) Dissection of synapse induction by neuroligins: Effect of a neuroligin mutation associated with autism, J. Biol. Chem. 280, 22365-22374.

14. Comoletti, D., Flynn, R., Jennings, L. L., Chubykin, A., Matsumura, T., Hasegawa, H., Sudhof, T. C., and Taylor, P. (2003) Characterization of the interaction of a recombinant soluble neuroligin-1 with neurexin-1 $\beta$, J. Biol. Chem. 278, 50497-50505.

15. Boucard, A. A., Chubykin, A. A., Comoletti, D., Taylor, P., and Sudhof, T. C. (2005) A splice code for trans-synaptic cell adhesion mediated by binding of neuroligin 1 to $\alpha$ - and $\beta$-neurexins, Neuron 48, 229-236.

16. Missler, M., Fernandez-Chacon, R., and Sudhof, T. C. (1998) The making of neurexins, J. Neurochem. 71, 1339-1347.

17. Rudenko, G., Nguyen, T., Chelliah, Y., Sudhof, T. C., and Deisenhofer, J. (1999) The structure of the ligand-binding domain of neurexin I- $\beta$ : Regulation of LNS domain function by alternative splicing, Cell 99, 93-101.

18. Ichtchenko, K., Hata, Y., Nguyen, T., Ullrich, B., Missler, M., Moomaw, C., and Sudhof, T. C. (1995) Neuroligin 1: A splice site-specific ligand for $\beta$-neurexins, Cell 81, 435-443.

19. Nguyen, T., and Sudhof, T. C. (1997) Binding properties of neuroligin 1 and neurexin $1 \beta$ reveal function as heterophilic cell adhesion molecules, J. Biol. Chem. 272, 26032-26039.

20. Black, D. L. (2003) Mechanisms of alternative pre-messenger RNA splicing, Annu. Rev. Biochem. 72, 291-336.

21. Wang, P., Yan, B., Guo, J. T., Hicks, C., and Xu, Y. (2005) Structural genomics analysis of alternative splicing and application to isoform structure modeling, Proc. Natl. Acad. Sci. U.S.A. 102, 18920-18925.

22. Comoletti, D., De Jaco, A., Jennings, L. L., Flynn, R. E., Gaietta, G., Tsigelny, I., Ellisman, M, H., and Taylor, P. (2004) The Arg451Cys-neuroligin-3 mutation associated with autism reveals a defect in protein processing, J. Neurosci. 24, 4889-4893.

23. Ushkaryov, Y. A., Hata, Y., Ichtchenko, K., Moomaw, C., Afendis, S., Slaughter, C. A., and Sudhof, T. C. (1994) Conserved domain structure of $\beta$-neurexins. Unusual cleaved signal sequences in receptor-like neuronal cell-surface proteins, J. Biol. Chem. 269, 11987-11992.

24. Demeler, B. (2005) UltraScan a comprehensive data analysis software package for analytical ultracentrifugation experiments, Modern Analytical Ultracentrifugation: Techniques and Methods (Scott, D. J., Harding, S. E., and Rowe, A. J., Eds.) pp 210-229, Royal Society of Chemistry, U.K.
25. Demeler, B. (2006) UltraScan Data Analysis Software, version 7.3. Department of Biochemistry, The University of Texas Health Science Center, San Antonio, TX, http:// www.ultrascan.uthscsa.edu.

26. Demeler, B., and van Holde, K. E. (2004) Sedimentation velocity analysis of highly heterogeneous systems, Anal. Biochem. 335, 279-288.

27. Cao, W., and Demeler, B. (2005) Modeling analytical ultracentrifugation experiments with an adaptive space-time finite element solution of the Lamm equation, Biophys. J. 89, 1589-1602.

28. Demeler, B., and Saber, H. (1998) Determination of molecular parameters by fitting sedimentation data to finite element solutions of the Lamm equation, Biophys. J. 74, 444-454.

29. Philo, J. SEDNTERP, version 1.06. http://jphilo.mailway.com/ download.htm.

30. Hoffman, R. C., Jennings, L. L., Tsigelny, I., Comoletti, D., Flynn, R. E., Sudhof, T. C., and Taylor, P. (2004) Structural characterization of recombinant soluble rat neuroligin 1: Mapping of secondary structure and glycosylation by mass spectrometry, Biochemistry 43, 1496-1506.

31. Johnsson, B., Lofas, S., and Lindqvist, G. (1991) Immobilization of proteins to a carboxymethyldextran-modified gold surface for biospecific interaction analysis in surface plasmon resonance sensors, Anal. Biochem. 198, 268-277.

32. Dean, C., Scholl, F. G., Choih, J., DeMaria, S., Berger, J., Isacoff, E., and Scheiffele, P. (2003) Neurexin mediates the assembly of presynaptic terminals, Nat. Neurosci. 6, 708-716.

33. Demeler, B., Saber, H., and Hansen, J. C. (1997) Identification and interpretation of complexity in sedimentation velocity boundaries, Biophys. J. 72, 397-407.

34. De Jaco, A., Comoletti, D., Kovarik, Z., Gaietta, G., Radic, Z., Lockridge, O., Ellisman, M. H., and Taylor, P. (2006) A mutation linked with autism reveals a common mechanism of endoplasmic reticulum retention for the $\alpha, \beta$-hydrolase fold protein family, $J$. Biol. Chem. 281, 9667-9676.

35. Graf, E. R., Kang, Y., Hauner, A. M., and Craig, A. M. (2006) Structure function and splice site analysis of the synaptogenic activity of the neurexin-1 $\beta$ LNS domain, J. Neurosci. 26, 42564265 .

36. Bell, M. V., Cowper, A. E., Lefranc, M. P., Bell, J. I., and Screaton, G. R. (1998) Influence of intron length on alternative splicing of CD44, Mol. Cell. Biol. 10, 5930-5941.

37. Bourne, Y., Taylor, P., and Marchot, P. (1995) Acetylcholinesterase inhibition by fasciculin: Crystal structure of the complex, Cell $83,503-512$.

38. Sussman, J. L., Harel, M., Frolow, F., Oefner, C., Goldman, A., Toker, L., and Silman, I. (1991) Atomic structure of acetylcholinesterase from Torpedo californica: A prototypic acetylcholinebinding protein, Science 253, 872-879.

39. Auranen, M., Varilo, T., Alen, R., Vanhala, R., Ayers, K., Kempas, E., Ylisaukko-Oja, T., Peltonen, L., and Jarvela, I. (2003) Evidence for allelic association on chromosome 3q25-27 in families with autism spectrum disorders originating from a subisolate of Finland, Mol. Psychiatry 8, 879-884.

40. Tentler, D., Johannesson, T., Johansson, M., Rastam, M., Gillberg, C., Orsmark, C., Carlsson, B., Wahlstrom, J., and Dahl, N. (2003) A candidate region for Asperger syndrome defined by two $17 \mathrm{p}$ breakpoints, Eur. J. Hum. Genet. 1, 189-195.

41. Thomas, N. S., Sharp, A. J., Browne, C. E., Skuse, D., Hardie, C., and Dennis, N. R. (1999) Xp deletions associated with autism in three females, Hum. Genet. 104, 43-48.

42. Jamain, S., Quach, H., Betancur, C., Rastam, M., Colineaux, C., Gillberg, I. C., Soderstrom, H., Giros, B., Leboyer, M., Gillberg, C., and Bourgeron, T. (2003) Paris Autism Research International Sibpair Study. Mutations of the X-linked genes encoding neuroligins NLGN3 and NLGN4 are associated with autism, Nat. Genet. 34, 27-29.

43. Laumonnier, F., Bonnet-Brilhault, F., Gomot, M., Blanc, R., David, A., Moizard, M. P., Raynaud, M., Ronce, N., Lemonnier, E., Calvas, P., Laudier, B., Chelly, J., Fryns, J. P., Ropers, H. H., Hamel, B. C., Andres, C., Barthelemy, C., Moraine, C., and Briault, S. (2004) X-linked mental retardation and autism are associated with a mutation in the NLGN4 gene, a member of the neuroligin family, Am. J. Hum. Genet. 74, 552-557.

44. Yan, J., Oliveira, G., Coutinho, A., Yang, C., Feng, J., Katz, C., Sram, J., Bockholt, A., Jones, I. R., Craddock, N., Cook, E. H., Vicente, A., and Sommer, S. S. (2005) Analysis of the neuroligin 3 and 4 genes in autism and other neuropsychiatric patients, Mol. Psychiatry 10, 329-332. 
45. Talebizadeh, Z., Lam, D. Y., Theodoro, M. F., Bittel, D. C., Lushington, G. H., and Butler, M. G. (2006) Novel splice isoforms for NLGN3 and NLGN4 with possible implications in autism, $J$. Med. Genet. 43, e21.
46. Zoghbi, H. Y. (2003) Postnatal neurodevelopmental disorders: Meeting at the synapse? Science 302, 826-830.

BI0614131 